\title{
Angular photogrammetric analysis of the soft tissue profile in 12-year-old southern Chinese
}

\author{
Cindi SY Leung ${ }^{1}$, Yanqi Yang ${ }^{1}$, Ricky WK Wong ${ }^{2}$, Urban Hägg ${ }^{1}$, John Lo ${ }^{3}$ and Colman McGrath ${ }^{4 *}$
}

\begin{abstract}
Introduction: To quantify average angular measurements that define the soft tissue profiles of 12-year-old southern Chinese and to determine gender differences.

Materials and methods: A random population sample of 514 12-year-old children was recruited (about 10\% of a Hong Kong Chinese birth cohort). Photographs were taken in natural head posture and 12 soft tissue landmarks were located on the photos to measure 12 angular measurements using ImageJ (V1.45s) for Windows. Approximately $10 \%$ of photographs were reanalyzed and method error was calculated. Angular norm values for the 12 parameters were determined and gender differences were assessed using 2 sample $T$-test with 95\% confidence interval.

Results: The response rate was 54.1\% (278/514). Norm values for the 12 angular measurements were generated. The greatest variability was found for the nasolabial (Cm-Sn-Ls) and labiomental (Li-Sm-Pg) angles. Gender differences were found in 4 angular parameters: vertical nasal angle (N-Prn/TV) $(p<0.05)$, cervicomental angle $(\mathrm{G}-\mathrm{Pg} / \mathrm{C}-\mathrm{Me})(\mathrm{p}<0.001)$, facial convexity angle $(G-S n-P g)(p<0.01)$ and total facial convexity angle $(G-P r n-P g)(p<0.01)$.

Conclusion: Norm values for 12 angular measurements among 12-year-old southern Chinese children were provided and some variability noted. Gender differences were apparent in several angular measurements. This study has implications in developing norm values for southern Chinese and for comparison with other ethnic groups.
\end{abstract}

Keywords: Photogrammetric analysis, Soft tissue profile, 12-year-old southern Chinese

\section{Introduction}

The assessment of the patients' soft tissue profile is a critical step in orthodontic diagnosis and treatment planning. Achieving a pleasing esthetic profile is an important goal of orthodontic therapy, and can influence the treatment decision to extract teeth or not [1].

In the early twentieth century, orthodontic treatment goals were limited to achieving a functional occlusion and stability of the dentition. Although soft tissue esthetics were noted, little could be done to alter the soft tissue profile [2].

The introduction of orthopaedic and craniofacial surgical techniques in the 1960s and 1970s has allowed facial harmony to be incorporated into treatment goals [3]. The introduction of skeletal anchorage techniques has also produced positive results. These advances in

\footnotetext{
* Correspondence: mcgrathc@hkucc.hku.hk

${ }^{4}$ Periodontology and Public Health, Faculty of Dentistry, The University of Hong Kong; Prince Philip Dental Hospital, 34 Hospital Road, Hong Kong, SAR, China

Full list of author information is available at the end of the article
}

technology have allowed greater improvements in facial profile aesthetic outcomes from orthodontic care.

In the past, orthodontic diagnosis and treatment planning has relied primarily on data from cephalometric studies. Numerous approaches have been developed for cephalometric analysis and many included soft tissue assessments [4-8]. Although cephalometric assessment serves as a useful guideline towards diagnosis and treatment planning, soft tissue profiles are of important consideration to attain improved facial appearance.

In cephalograms, the soft tissue structures are recorded only in profile and limited to the anterior-most outline. Furthermore, patients are typically unaccustomed to viewing and interpreting cephalograms or their tracings whereas photographs, on the other hand, provide a more amenable approach to documenting and assessing the soft tissues of the face [9].

There is marked variation in the soft tissue covering the dentoskeletal framework [10,11]. Longitudinal studies have indicated that the soft tissue profile does not 
directly follow the underlying skeletal profile [12]. Thus there is a need to 'directly' study the parameters of the soft tissue lateral profile. Various authors have studied the soft tissue profiles using photogrammetry [13-16].

An increase in dental awareness has created a great demand for orthodontic treatment in Chinese populations [17]. Whilst norms have been established for Caucasian populations regarding both cephalometric readings and lateral soft tissue profile parameters, to date, there is a lack of study in this area for the Chinese population. There is thus, a great need to establish Chinese population norms.

The aims of the present study were (1) to quantify average parameters that define the soft tissue profiles' of 12-year-old southern Chinese; and (2) to describe any gender differences found.

\section{Materials and methods}

\section{Sample}

A population-wide epidemiological study was conducted among 12-year-old children in Hong Kong SAR, China. Ethical approval was obtained by the local Institutional Review Board (Reference Number: UW 09-453). Support was obtained by a grant from the Research Grants Council of the Hong Kong Special Administrative Region, China. A random sample of $10 \%$ of all secondary schools in Hong Kong SAR was selected and within each school children were invited to participate. Their parents provided written informed consent and the children provided their ascent. A sample of 514 (259 males, $255 \mathrm{fe-}$ males) was recruited, approximately $10 \%$ of a Chinese birth cohort. Sixteen subjects (3.1\%) who had history of orthodontic treatment or were undergoing active orthodontic treatment were excluded from the final sample.

\section{Data collection}

\section{Photographic set up and record taking}

Data collection was done 'in the field' (non-clinical setting) at available classrooms designated by each school. The photographic set up consisted of a Canon EOS 400D (Canon, Shimomaruko, Ohta-ku, Tokyo, Japan) camera with Canon EF-S $60 \mathrm{~mm} \mathrm{f/2.8} \mathrm{Macro} \mathrm{USM} \mathrm{Lens} \mathrm{and}$ Canon MR-14EX TTL Macro Ring lite Flash. Subjects were positioned against a scale backdrop of $1 \mathrm{~cm}$ increment with plumbline which indicated the true vertical (TV). A vertical standing mirror was positioned out of the frame perpendicular to the left side of the background set up for improved reproducibility of the natural head posture [18].

Subjects were asked to remove glasses or other accessories, which may obstruct the profile. They were then instructed to a standing position, asked to relax with both arms hanging down at their sides and look straight into their eyes in the mirror with lips in a relaxed position. The right side profile was taken in natural head posture (NHP).

\section{Selection of landmarks and angular parameters}

Twelve soft tissue landmarks (Table 1, Figure 1) and 12 angular parameters (Table 2, Figures 2 and 3) were selected based on a modification of Fernández-Riveiro [19] and Malkoç [20] photogrammetric methods and in addition, a variable (G-Pg/TV) to assess the angle of head posture was also assessed.

\section{Selection of photographs}

Photographs were screened for 'usability' i.e. feasibility of identifying landmarks and angular measurements. Photographs were excluded if: 1) landmarks were obstructed or unclear; 2) 'out of focus'; 3) subjects exhibiting obvious lip muscle strain or open mouth posture; 4) subjects who exhibited facial expressions that were not neutral (i.e smiling); 5) head tilting up or down; 6) Photographs where the plumbline or scale backdrop were not visible.

A final sample of 278 subjects (166 males, 112 females) was recruited.

\section{Digitalization}

Photographs were orientated to true vertical using ImageJ V1.45s and cropped to show the head and neck area only. The 12 soft tissue landmarks were located (Table 1,

Table 1 Landmarks, abbreviations and reference lines employed in this study

\begin{tabular}{ll}
\hline Abbreviations & Landmark/reference point \\
\hline $\mathbf{G}$ & Glabella \\
$\mathbf{N}$ & Nasion \\
Prn & Pronasal \\
Cm & Columella \\
Ln & Subnasale \\
Li & Labiale Superius \\
Sm & Labiale Inferius \\
Pg & Supramental \\
Me & Pogonion \\
C & Menton \\
Trg & Cervical \\
sTV & Tragus \\
iTV & Superior point of true vertical \\
Ort & Inferior point of true vertical \\
& Junction point of true vertical \& \\
Reference point and lines & true horizontal \\
True vertical & \\
True vertical in nasion & sTV - iTV \\
True horizontal & Trg-Ort (perpendicular to TV through Trg) \\
\hline
\end{tabular}




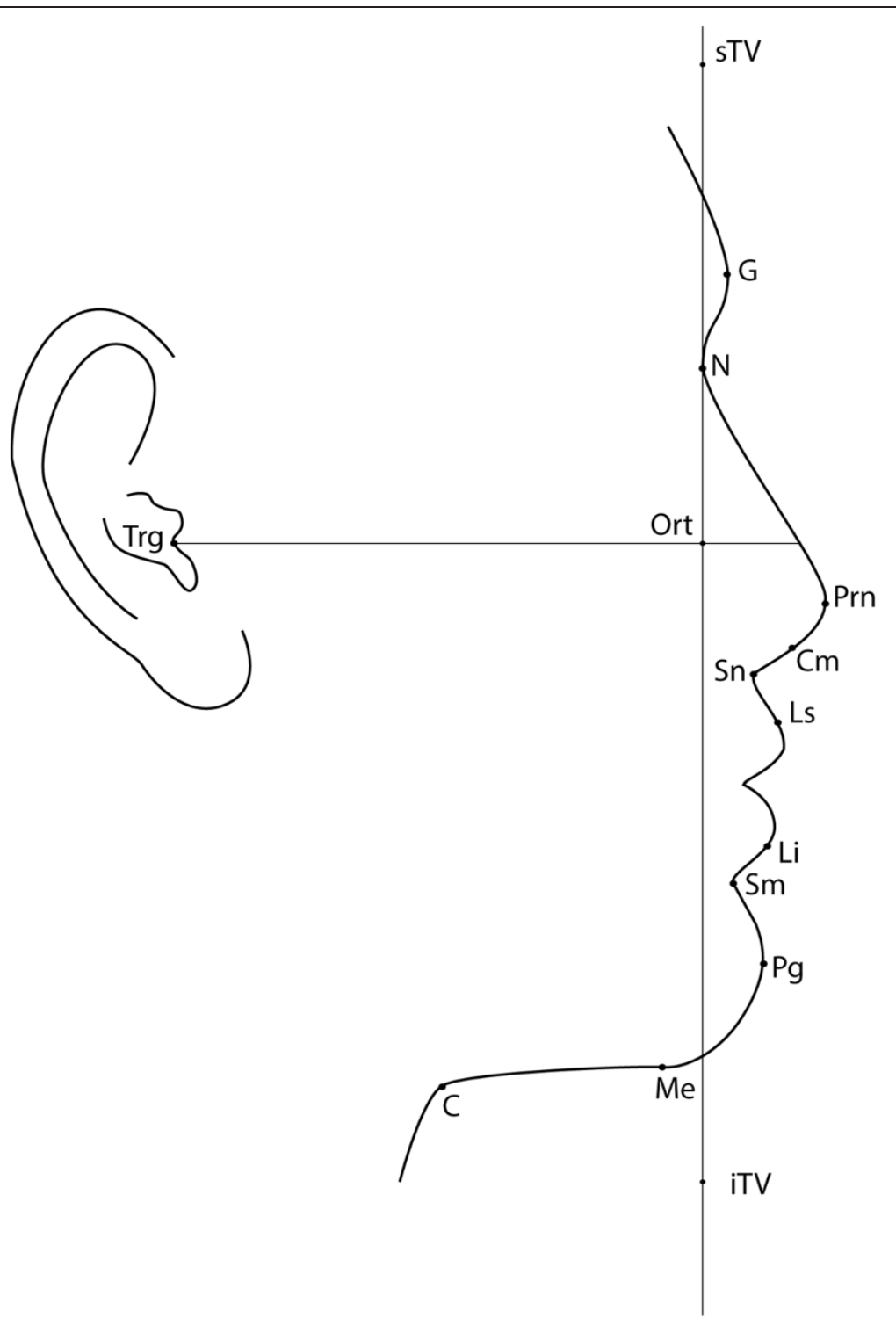

Figure 1 Soft tissue landmarks and reference lines. G, glabella; N, nasion; Prn, pronsal; Cm, columella; Sn, subnasal; Ls, Labiale Superius, Li, Labiale Inferius; Sm, supramental; Pg, pogonion; Me, menton; C, cervical; Trg, tragus; sTV, superior point of true vertical; iTV, inferior point of true vertical; Ort point, junction point of true vertical and true horizontal. Reference lines: sTV-iTV, true vertical; N-Ort (parallel to TV through nasion), true vertical in nasion; Trg-Ort (perpendicular to TV through Trg), true horizontal.

Figure 1) to measure 12 angular measurements (Table 2, Figure 2, 3). Two arbitrary points were defined parallel to the true vertical through the $\mathrm{N}$ point to identify the 'true vertical in Nasion'. Reference lines were created using Microsoft Paint ${ }^{\circ}$. The same trained and calibrated examiner conducted all photographic measurements.

\section{Statistical analysis}

Descriptive statistics were produced of mean, standard deviation and range (maximum, minimum) for each parameter. Gender differences were determined using t- test statistics with 95\% confidence interval provided by SPSS (V19) (IBM Corporation, Armonk, New York, USA).
To assess method error, about $10 \%$ of randomly selected subjects were re-analyzed for intra-examiner method error analysis as calculated by Dahlberg's formula [21]. Intra-class correlation coefficients were calculated by SPSS (V19).

\section{Results}

Among the 514 subjects, $45.9 \%$ (236) were excluded in the selection of photographs according to the exclusion criteria, providing an overall response rate of 54.1\% (278/514).

Intra-examiner method error was determined based on about $10 \%$ of the sample (Table 3 ). The angles with the highest method error were the Nasolabial: $2.50^{\circ}$, labiomental angle: $2.76^{\circ}$ and nasal angle: $2.52^{\circ}$. ICC 
Table 2 Description of angular measurements

\begin{tabular}{ll}
\hline Parameter & Description \\
\hline Nasofrontal & G-N-Prn \\
Vertical nasal & $\mathrm{N}-\mathrm{Prn} / \mathrm{TV}$ \\
Nasolabial & $\mathrm{Cm}-\mathrm{Sn}-\mathrm{Ls}$ \\
Labiomental & $\mathrm{Li}-\mathrm{Sm}-\mathrm{Pg}$ \\
Nasal angle & $\mathrm{Sn}-\mathrm{Cm} / \mathrm{N}-\mathrm{Prn}$ \\
Cervicomental & $\mathrm{G}-\mathrm{Pg} / \mathrm{C}-\mathrm{Me}$ \\
Medium facial third & $\mathrm{N}-\mathrm{Trg}-\mathrm{Sn}$ \\
Inferior facial third & $\mathrm{Sn}-\mathrm{Trg}-\mathrm{Me}$ \\
Head position & $\mathrm{Sn}-\mathrm{Sm} / \mathrm{TH}$ \\
Facial convexity & $\mathrm{G}-\mathrm{Sn}-\mathrm{Pg}$ \\
Total facial convexity & $\mathrm{G}-\mathrm{Prn}-\mathrm{Pg}$ \\
Glabella pogonion vertical & $\mathrm{G}-\mathrm{Pg} / \mathrm{TV}$ \\
\hline
\end{tabular}

values (Table 4) were greater than 0.8 for all angles, indicating good reliability.

Descriptive statistics (Mean (SD) and range) of the 12 angular parameters are provided in Table 5 . The greatest variability was found for the nasolabial (male: $64.56^{\circ}$ to $132.80^{\circ}$, female: $73.33^{\circ}$ to $123.89^{\circ}$ ) and labiomental (male: $93.36^{\circ}$ to $158.11^{\circ}$, female: $98.27^{\circ}$ to $164.11^{\circ}$ ) angles. These angles also exhibited the highest method error.

Gender differences were found in four parameters including the vertical nasal angle $(\mathrm{N}-\mathrm{Prn} / \mathrm{TV}), \mathrm{p}<0.05$; Cervicomental angle (G-Pg/C-Me), $\mathrm{p}<0.001$; facial convexity angle (G-Sn-Pg), $\mathrm{p}<0.01$; and total facial convexity angle (G-Prn-Pg), $\mathrm{p}<0.01$. Larger vertical nasal angle was found in males $\left(26.95^{\circ} \pm 3.69^{\circ}\right)$ compared to females $\left(25.97^{\circ} \pm 3.67^{\circ}\right)$ and a larger cervicomental angle was found in males $\left(97.05^{\circ} \pm 7.76^{\circ}\right)$ compared to females $\left(92.58^{\circ} \pm 6.64^{\circ}\right)$. Females exhibited larger overall facial convexity $\left(169.85^{\circ} \pm 4.83^{\circ}\right)$ and total facial convexity

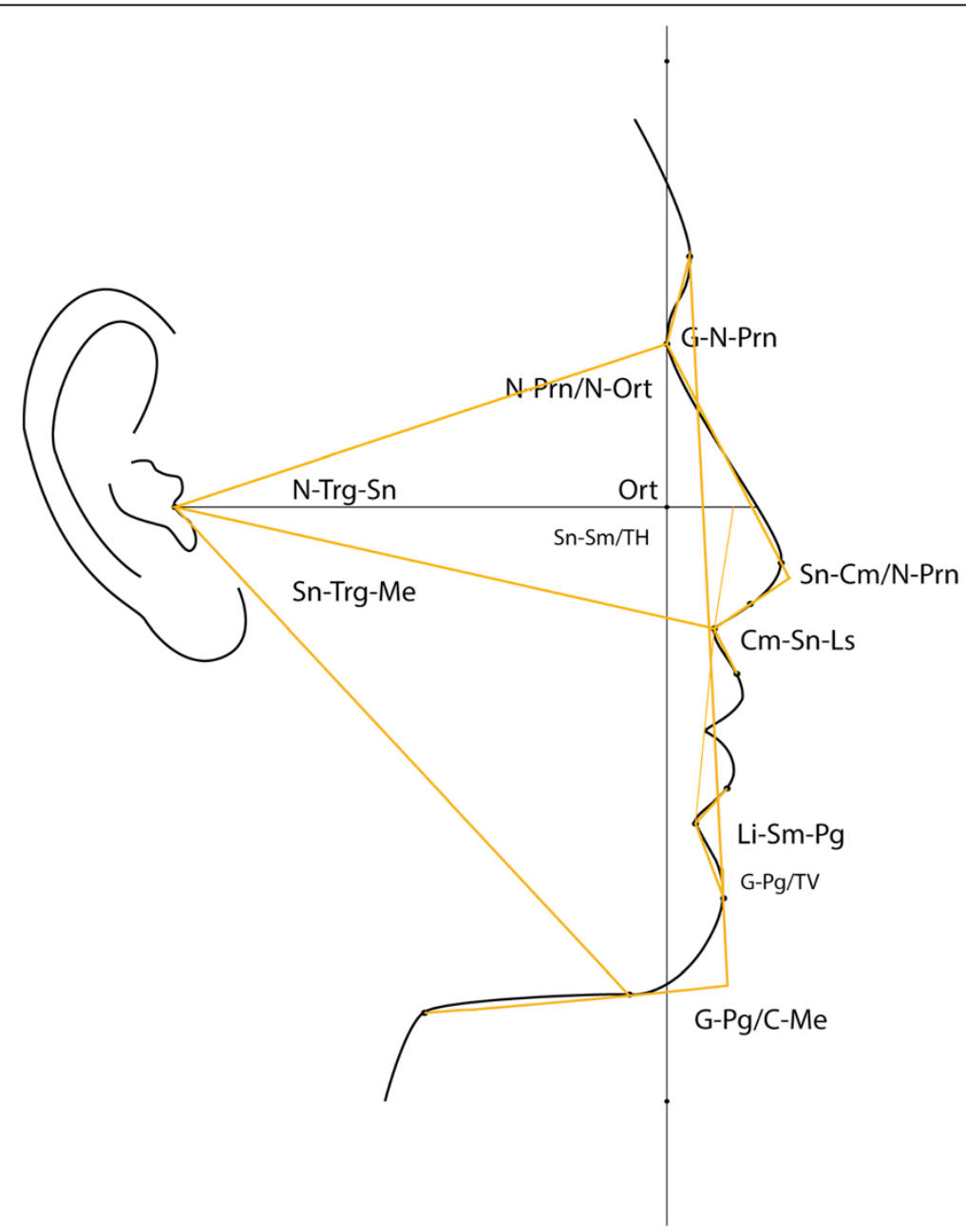

Figure 2 Angular measurements: G-N-Prn, Nasofrontal angle; N-Prn/N-Ort, vertical nasal angle; $\mathrm{Cm}-\mathrm{Sn}$-Ls, nasolabial angle; Li-Sm-Pg, labiomental angle; Sn-Cm/N-Prn, Nasal angle; G-Pg/C-Me, cervicomental angle; N-Trg-Sn, angle of medium facial third; Sn-Trg-Me, angle of inferior facial third; $\mathrm{Sn}-\mathrm{Sm} / \mathrm{TH}$, angle of head position; G-Pg/TV, glabella pogonion vertical. 


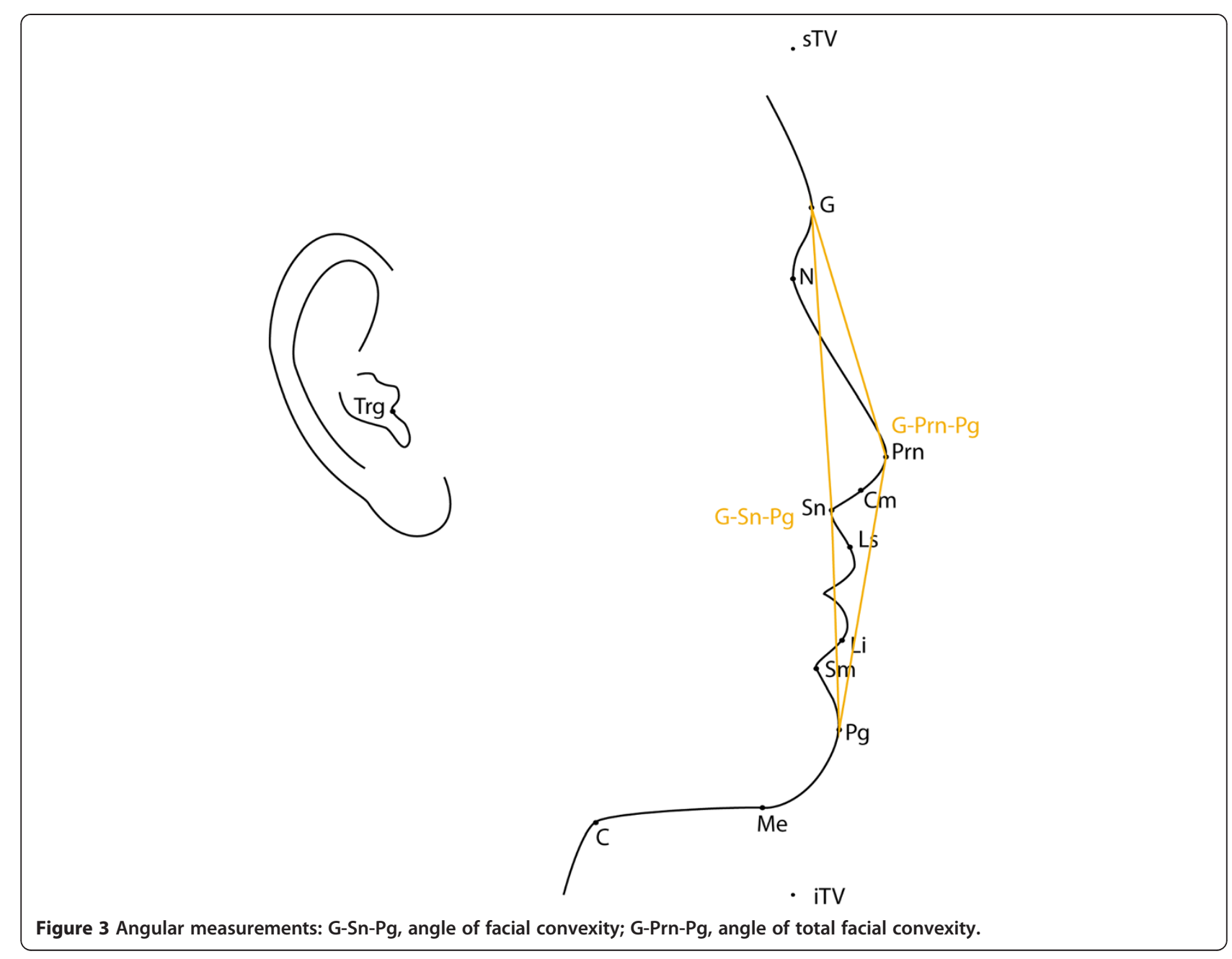

Table 3 Method error according to Dahlberg's formula

\begin{tabular}{ll}
\hline Parameter & Method error $\left(^{\circ}\right)$ \\
\hline Nasofrontal & 0.76 \\
Vertical Nasal & 0.3 \\
Nasolabial & 2.5 \\
Labiomental & 2.76 \\
Nasal angle & 2.52 \\
Cervicomental & 0.5 \\
Medium facial third & 0.28 \\
Inferior facial third & 0.38 \\
Angle of head position & 0.25 \\
Facial convexity & 0.44 \\
Total facial convexity & 0.45 \\
Glabella-pogonion vertical & 0.11 \\
\hline
\end{tabular}

Table 4 Intra-class correlation coefficients

\begin{tabular}{ll}
\hline Parameter & ICC value \\
\hline Nasofrontal & 0.982 \\
Vertical Nasal & 0.991 \\
Nasolabial & 0.945 \\
Labiomental & 0.939 \\
Nasal angle & 0.89 \\
Cervicomental & 0.997 \\
Medium facial third & 0.982 \\
Inferior facial third & 0.975 \\
Angle of head position & 0.998 \\
Facial convexity & 0.993 \\
Total facial convexity & 0.993 \\
Glabella-pogonion vertical & 0.998 \\
\hline
\end{tabular}


Table 5 Descriptive data for measurements in males and females

\begin{tabular}{|c|c|c|c|c|c|c|c|c|c|}
\hline \multirow[b]{2}{*}{ Parameter } & \multicolumn{2}{|c|}{ Male $(n=166)$} & \multirow[b]{2}{*}{ Min } & \multirow[b]{2}{*}{ Max } & \multicolumn{2}{|c|}{ Female $(n=112)$} & \multirow[b]{2}{*}{ Min } & \multirow[b]{2}{*}{ Max } & \multirow[b]{2}{*}{$P$ value } \\
\hline & Mean & S.D & & & Mean & S.D & & & \\
\hline Nasofrontal & 143.94 & 4.97 & 126.52 & 157.36 & 144.68 & 4.51 & 131.17 & 157.14 & 0.212 \\
\hline Vertical Nasal & 26.95 & 3.69 & 18.25 & 39.34 & 25.97 & 3.67 & 16.84 & 34.80 & $0.031^{*}$ \\
\hline Nasolabial & 99.03 & 11.52 & 64.56 & 132.80 & 99.05 & 10.24 & 73.33 & 123.89 & 0.991 \\
\hline Labiomental & 132.56 & 12.46 & 93.36 & 158.11 & 135.30 & 11.43 & 98.27 & 164.11 & 0.064 \\
\hline Nasal angle & 91.77 & 8.74 & 66.18 & 110.68 & 91.18 & 7.87 & 67.59 & 107.82 & 0.565 \\
\hline Cervicomental & 97.05 & 7.76 & 76.26 & 114.77 & 92.58 & 6.64 & 75.55 & 113.18 & $0.000^{* * *}$ \\
\hline Medium facial third & 28.94 & 2.36 & 24.32 & 36.41 & 28.65 & 2.23 & 22.33 & 34.52 & 0.299 \\
\hline Inferior facial third & 36.92 & 2.90 & 24.91 & 43.29 & 36.55 & 2.64 & 30.17 & 43.05 & 0.284 \\
\hline Angle of head position & 79.28 & 5.39 & 63.01 & 93.51 & 79.46 & 5.34 & 68.57 & 94.13 & 0.785 \\
\hline Facial convexity & 168.10 & 5.10 & 154.22 & 179.82 & 169.85 & 4.83 & 155.91 & 179.57 & $0.004^{* *}$ \\
\hline Total facial convexity & 147.03 & 5.14 & 130.89 & 164.21 & 148.83 & 4.58 & 136.96 & 160.00 & $0.003^{* *}$ \\
\hline Glabella-pogonion vertical & 3.59 & 2.63 & 0.00 & 11.81 & 3.93 & 2.39 & 0.00 & 10.37 & 0.277 \\
\hline
\end{tabular}

${ }^{*} \mathrm{P}<0.05$; ${ }^{*} \mathrm{P}<0.01 ;{ }^{*}{ }^{*} \mathrm{P}<0.00$.

angles $\left(148.83^{\circ} \pm 4.58^{\circ}\right)$ compared to males $\left(168.10^{\circ} \pm\right.$ $\left.5.10^{\circ}\right)$ and $\left(147.03^{\circ} \pm 5.14^{\circ}\right)$ respectively.

\section{Discussion}

For the most part photogrammetric studies have been conducted on small, non-random, clinical samples. This study sought to provide population norms for southern Chinese children and was obtained from a random population sample of 12-year-old children. The response rate to the study was $54.1 \%$. The loss of participants was due to a number of factors including subjects with a history of orthodontic treatment, obstruction of landmarks and problems with photo image quality. This highlights the challenges faced in performing photogrammetric studies 'in the field' (in outreach settings/in non-clinical settings). Nonetheless, the sample size (of 278) was adequate to provide populations norms and to identify gender differences and is one of the largest sample size for which photogrammetric assessments have been conducted in a random population sample to date.

Norm angular values were provided for 12 angular measurements, which reflect a comprehensive range of angular assessments. Of note certain angular measurements (nasolabial \& labiomental) had considerable variability. This indicates a great degree of individual variation in lip profiles amongst 12-year-olds. Similar findings in large variability of the nasolabial and labiomental angle were observed in various other studies [19,20,22,23]. Varga's cephalometric study [22] on Croatian adolescents observed nasolabial $\left(106.39^{\circ} \pm 10.36\right)$ and labiomental $\left(130.36^{\circ} \pm 12.58\right)$ angles of large variability. Malkoç [20] reported large variability for the nasolabial angle (male: $75.40^{\circ}$ to $126.90^{\circ}$, female: $81.71^{\circ}$ to $129.90^{\circ}$ ) and the labiomental angle (male: $113.00^{\circ}$ to $142.60^{\circ}$, female: $108.05^{\circ}$ to $\left.156.50^{\circ}\right)$ in a sample of Class I Turkish adults. Riveiro [19] observed similar trends in variability of the nasolabial (male: $71.7^{\circ}$ to $137.6^{\circ}$, female: $76.5^{\circ}$ to $134.5^{\circ}$ ) and labiomental angles (male: $113.2^{\circ}$ to $153.1^{\circ}$, female: $95.8^{\circ}$ to $159.8^{\circ}$ ).

The mean values obtained from the present sample can be used for comparison with records of subjects evaluated using the same analysis and photogrammetric technique. Angular photogrammetic parameters can aid orthodontists and other specialists to evaluate the soft tissue aspects of the facial profile with regards to treatment planning.

In terms of method error, it was generally found to be highest for labiomental angle $\left(2.76^{\circ}\right)$, Nasolabial angle $\left(2.50^{\circ}\right)$ and Nasal angle $\left(2.52^{\circ}\right)$. This should be borne in mind in interpreting the results for clinical use. The assessment of method error is consistent to the findings of Malkoç [20] and Riveiro [19] which reported a high method error for the labiomental angle at 2.16 and 4.5 respectively. Regarding the nasolabial parameter, Malkoç [20] reported a method error of $1.60^{\circ}$ and Riveiro [18] reported a method error of $4^{\circ}$. Riveiro [19] also reported a high method error for the nasal angle $\left(3.5^{\circ}\right)$.

Gender difference in 4 angular parameters were observed: vertical nasal angle, cervicomental angle, facial convexity angle and total facial convexity angle (N-Prn/TV; G-Pg/C-Me; G-Sn-Pg; G-Prn-Pg). Males had a larger vertical nasal angle $\left(26.95^{\circ} \pm 3.69^{\circ}\right)$ than females $\left(25.97^{\circ} \pm 3.67^{\circ}\right.$ degrees). This concurs with findings from Riveiro [19] photogrammetric study on 18-20 year old Caucasian subjects. Riveiro [19] reported gender differences in the vertical nasal angle being greater in males $\left(33.8^{\circ} \pm 5.82^{\circ}\right)$ compared to females $\left(31.25^{\circ} \pm 4.5^{\circ}\right)$. Malkoç [20] reported no gender differences in the vertical nasal angle in a dental Class I Adult Turkish subject group between males $\left(26.57^{\circ} \pm 3.16^{\circ}\right)$ and females $\left(26.21^{\circ} \pm 4.07^{\circ}\right)$ with mean values comparable to the ones found in this study. 
A larger cervicomental angle was found in males $\left(97.05^{\circ} \pm 7.76^{\circ}\right)$ compared to females $\left(92.58^{\circ} \pm 6.64^{\circ}\right)$. This concurs with the findings of Malkoç [20] with males exhibiting $104.86^{\circ} \pm 9.86^{\circ}$ and females $95.64^{\circ} \pm 7.74^{\circ}$. Riveiro [19] also found gender differences in the cervicomental angle but reported females $\left(84.18^{\circ} \pm 6.65^{\circ}\right)$ exhibiting a larger cervicomental angle compared to males $\left(79.85^{\circ} \pm 7.19^{\circ}\right)$.

Females exhibited larger facial convexity $\left(169.85^{\circ} \pm\right.$ $\left.4.83^{\circ}\right)$ and total facial convexity angles $\left(148.83^{\circ} \pm 4.58^{\circ}\right)$ compared to males $\left(168.10^{\circ} \pm 5.10^{\circ}\right)$ and $\left(147.03^{\circ} \pm 5.14^{\circ}\right)$ respectively. Gender differences were not found in the study of adult subjects by Anić-Milošević [22] Malkoç [20] and Riveiro [19]. These differences may be due to variations in age groups studied or ethnic differences. Varga's cephalometric study [23] on Class I Croatian subjects reported comparable total facial convexity angle of $141.55^{\circ}$ in $12-15$ year old subjects. Bergman's longitudinal study of cephalometric soft tissue profile traits between 6 and 18 years found the facial convexity angle remained relatively constant during growth [24].

Reference values of adolescents from other ethnic groups have been compared to our findings. The nasolabial angle as a reflection of the relationship between the base of the nose and the upper lip was reported to be $99.05^{\circ} \pm 10.24^{\circ}$ in females and $99.03^{\circ} \pm 11.52^{\circ}$ in males. Farkas [25] reported similar measurements in 13 year old Canadian Whites with males: $98.6^{\circ} \pm 9.4^{\circ}$ and females $100.9^{\circ} \pm 9.3^{\circ}$. Yuen [26] reported in 13 year-old southern Chinese the findings of $102.7^{\circ} \pm 11.1^{\circ}$ in males and $101.6^{\circ} \pm 11.3^{\circ}$ in females. Burstone reported a significantly smaller mean of $73.8^{\circ} \pm 8.0^{\circ}$ degrees measurement in 13 to 15 year old Caucasian children. Varga's cephalometric study [23] on Class I Croatian children aged 12-15 years old reported a mean nasolabial angle of $106.39^{\circ}$.

The labiomental angle was reported to be $132.56^{\circ}$ in males and $135.30^{\circ}$ in females which is comparable to the findings of Yuen [26] who reported a mean of $134.3^{\circ}$ in males and $138.3^{\circ}$ in females in 13-year-old Southern Chinese children. Varga [23] also reported a comparable result of $130.36^{\circ}$ in 12-15 Croatian 12-15 year-olds.

Longitudinal follow-up for this epidemiological study can be anticipated to allow further assessments of changes in soft tissue profile with growth in the Southern Chinese population.

\section{Conclusions}

The following conclusions were drawn from the present study:

1. Norm values for the lateral soft tissue profile were presented for 12-year-old Southern Chinese population
2. High variability was found for the nasolabial, labiomental angles. These angles also exhibited high method error and should be borne in mind when interpreting results for clinical use.

3. There are gender differences in the vertical nasal, cervicomental, facial convexity and total facial convexity angles.

\section{Competing interests}

The authors declare that they have no competing interests.

\section{Authors' contributions}

$\mathrm{CL}$ completed all the measurement and drafted the manuscript. YY helped with organizing the survey, data analysis and drafted the manuscript. RW helped with the arrangement of the survey. UH calibrated the examiner and revised the manuscript. $J$ calibrated the examiner and helped with data analysis. CM designed the whole study and amended the manuscript. All authors read and approved the final manuscript.

\section{Acknowledgement}

I would like to thank Mr Shadow Yeung for his support and collaboration in the statistical analysis of this project, Ms Tracy Leung for her assistance in the illustrations. I would also like to extend my appreciation to the members of the research staff involved in the collaboration of the birth cohort research study.

\section{Author details}

${ }^{1}$ Paediatric Dentistry and Orthodontics, Faculty of Dentistry, The University of Hong Kong, Hong Kong, HKSAR, China. ${ }^{2}$ Department of Dentistry Maxillofacial Surgery, United Christian Hospital, Hong Kong, HKSAR, China. ${ }^{3}$ Oral and Maxillofacial surgery, Faculty of Dentistry, The University of Hong Kong, Hong Kong, HKSAR, China. ${ }^{4}$ Periodontology and Public Health, Faculty of Dentistry, The University of Hong Kong; Prince Philip Dental Hospital, 34 Hospital Road, Hong Kong, SAR, China.

Received: 15 July 2014 Accepted: 12 December 2014

Published online: 24 December 2014

\section{References}

1. Ackerman $J$, Proffit WR: Soft tissue limitations in orthodontics: treatment planning guidelines. Angle Orthod 1997, 67:327-336.

2. McLaughlin RP, Bennett C: Orthodontic management of the dentition with the preadjusted appliance. 3rd edition. Oxford: Isis Medical Media Ltd; 1997:196-199.

3. Roos B: A comparison of soft tissue prediction tracings using the Andrews and Ricketts diagnostic techniques. West Virginia University 2003: thesis

4. Merrifield $\mathrm{LL}$ : The profile line as an aid in critically evaluating facial esthetics. Am J Orthod 1966, 52:804-822.

5. Ricketts RM: Esthetics, environment, and the law of lip relation. Am J Orthod 1968, 54:272-289.

6. Burstone CJ, James RB, Legan H, Murphy GA, Norton LA: Cephalometrics for orthognathic surgery. J Oral Surg 1978, 36:269-277.

7. Lines PA, Lines RR, Lines CA: Profilemetrics and facial esthetics. Am J Orthod 1978, 73:648-657.

8. Holdaway RA: A soft-tissue cephalometric analysis and its use in orthodontic treatment planning Part I. Am J Orthod 1983, 84:1-28.

9. Bishara SE, Cummins DM, Jorgensen GJ, Jakobsen JR: A computer assisted photogrammetric analysis of soft tissue changes after orthodontic treatment. Part I: methodology and reliability. Am J Orthod Dentofacial Orthop 1995, 107:633-639.

10. Burstone CJ: The Integumental Profile. Am J Orthod 1958, 44:1-25.

11. Burstone CJ: The Integumental Contour and Extension Patterns. Angle Orthod 1959, 29:93-104.

12. Subtelny JD: A longitudinal study of soft tissue facial structures and their profile characteristics, defined in relation to underlying skeletal structures. Am J Orthod 1959, 45:481-507.

13. Stoner MM: A photometric analysis of the facial profile: A method of assessing facial change induced by orthodontic treatment. Am J Orthod $1955,41: 453-469$. 
14. Peck H, Peck S: A concept of facial esthetics. Angle Orthod 1970, 40:284-318.

15. Arnett GW, Bergman RT: Facial keys to orthodontic diagnosis and treatment planning Part I. Am J Orthod Dentofacial Orthop 1993, 103:299-312.

16. Arnett GW, Bergman RT: Facial keys to orthodontic diagnosis and treatment planning Part II. Am J Orthod Dentofacial Orthop 1993, 103:395-411.

17. Wang G, Hagg U, Ling J: The orthodontic treatment need and demand of Hong Kong Chinese children. Chin J Dent Res 1999, 2:84-92.

18. Cooke MS, Wei SH: The reproducibility of natural head posture: a methodological study. Am J Orthod Dentofacial Orthop 1988, 93:280-288.

19. Fernández-Riveiro P, Smyth-Chamosa E, Suárez-Quintanilla D, Suárez-Cunqueiro M: Angular photogrammetric analysis of the soft tissue facial profile. Eur J Orthod 2003, 25:393-399.

20. Malkoç S, Demir A, Uysal T, Canbuldu N: Angular photogrammetric analysis of the soft tissue facial profile of Turkish adults. Eur J Orthod 2009, 31:174-179.

21. Dahlberg G: Statistical methods for medical and biological students. London: George Allen and Unwin Ltd; 1940

22. Anić-Milošević S, Lapter-Varga M, Šlaj M: Analysis of the soft tissue facial profile by means of angular measurements. Eur J Orthod 2008, 30:135-140.

23. Lapter Varga M, Anić-Milošević S, Vusić A, Slaj M, Varga S, Perinić M, Slaj M: Soft tissue facial profile of normal dental and skeletal subjects in Croatian population aged 12 to 15 years. Coll Antropol 2008, 32:523-528.

24. Bergman RT, Waschak J, Borzabadi-Farahani A, Murphy NC: Longitudinal study of cephalometric soft tissue profile traits between the ages of 6 and 18 years. Angle Orthod 2014, 84:48-55.

25. Farkas LG: Anthropometry of the head and face in medicine. New York: Elsevier; 1981. ISBN 0444005579

26. Yuen SW, Hiranaka DK: A photographic study of the facial profiles of southern Chinese adolescents. Quintessence Int 1989, 20:665-676.

\section{Submit your next manuscript to BioMed Central and take full advantage of:}

- Convenient online submission

- Thorough peer review

- No space constraints or color figure charges

- Immediate publication on acceptance

- Inclusion in PubMed, CAS, Scopus and Google Scholar

- Research which is freely available for redistribution 